\title{
Unexpected structural complexity of supernumerary marker chromosomes characterized by microarray comparative genomic hybridization
}

\author{
Karen D Tsuchiya*1,2, Kent E Opheim ${ }^{1,2}$, Mark C Hannibal ${ }^{3}$, Anne V Hing3, \\ Ian A Glass ${ }^{3}$, Michael L Raff ${ }^{3}$, Thomas Norwood ${ }^{4}$ and Beth A Torchia ${ }^{5}$
}

Address: ${ }^{1}$ Department of Laboratories, Children's Hospital \& Regional Medical Center, Seattle, WA, USA, ${ }^{2}$ Department of Laboratory Medicine, University of Washington School of Medicine, Seattle, WA, USA, ${ }^{3}$ Department of Pediatrics, University of Washington School of Medicine, Seattle, WA, USA, ${ }^{4}$ Department of Pathology, University of Washington School of Medicine, Seattle, WA, USA and ${ }^{5}$ Signature Genomic Laboratories, LLC, Spokane, WA, USA

Email: Karen D Tsuchiya* - karen.tsuchiya@seattlechildrens.org; Kent E Opheim - kent.opheim@seattlechildrens.org;

Mark C Hannibal - mhanni@u.washington.edu; Anne V Hing - anne.hing@seattlechildrens.org; Ian A Glass - ian.glass@seattlechildrens.org; Michael L Raff - michael.raff@seattlechildrens.org; Thomas Norwood - hyno@u.washington.edu;

Beth A Torchia - torchia@signaturegenomics.com

* Corresponding author

Published: 2I April 2008

Molecular Cytogenetics 2008, 1:7 doi:10.1 186/1755-8166-1-7
Received: 6 March 2008

Accepted: 21 April 2008

This article is available from: http://www.molecularcytogenetics.org/content/I/I/7

(c) 2008 Tsuchiya et al; licensee BioMed Central Ltd.

This is an Open Access article distributed under the terms of the Creative Commons Attribution License (http://creativecommons.org/licenses/by/2.0), which permits unrestricted use, distribution, and reproduction in any medium, provided the original work is properly cited.

\begin{abstract}
Background: Supernumerary marker chromosomes (SMCs) are structurally abnormal extra chromosomes that cannot be unambiguously identified by conventional banding techniques. In the past, SMCs have been characterized using a variety of different molecular cytogenetic techniques. Although these techniques can sometimes identify the chromosome of origin of SMCs, they are cumbersome to perform and are not available in many clinical cytogenetic laboratories. Furthermore, they cannot precisely determine the region or breakpoints of the chromosome(s) involved. In this study, we describe four patients who possess one or more SMCs (a total of eight SMCs in all four patients) that were characterized by microarray comparative genomic hybridization (array CGH).
\end{abstract}

Results: In at least one SMC from all four patients, array CGH uncovered unexpected complexity, in the form of complex rearrangements, that could have gone undetected using other molecular cytogenetic techniques. Although array $\mathrm{CGH}$ accurately defined the chromosome content of all but two minute SMCs, fluorescence in situ hybridization was necessary to determine the structure of the markers.

Conclusion: The increasing use of array CGH in clinical cytogenetic laboratories will provide an efficient method for more comprehensive characterization of SMCs. Improved SMC characterization, facilitated by array $\mathrm{CGH}$, will allow for more accurate SMC/phenotype correlation. 


\section{Background}

Supernumerary marker chromosomes (SMCs) are structurally abnormal extra chromosomes that cannot be unambiguously identified by conventional banding techniques. A comprehensive description of SMCs can provide valuable information for genetic counseling, yet their extreme heterogeneity in size, structure, and chromosomal origin has resulted in limited characterization of many markers in clinical laboratories. In the case of SMCs containing satellites, targeted fluorescent in situ hybridization (FISH) testing for the most likely candidates, such as the inv $\operatorname{dup}(15 q)$ and the inv $\operatorname{dup}(22 q)$, are often employed; however, in the absence of an initial positive result, subsequent FISH analysis using individual probes becomes inefficient and costly. Furthermore, SMCs that lack satellites may have gone unclassified in many laboratories in the past.

A variety of molecular cytogenetic techniques that provide more comprehensive analysis in a single or a few experiments have been described for SMC characterization. Twenty-four color FISH, multicolor banding, centromerespecific multicolor FISH (cenM-FISH), subcentromerespecific multicolor FISH (subcenM-FISH), and microdissection followed by reverse FISH may all provide identification of the chromosome of origin of SMCs [1-4], but many of these techniques are not utilized by or accessible to most clinical laboratories. Even if 24-color FISH is readily available, this technique can result in ambiguous classification or misclassification of SMCs, particularly if they are small. In addition, these multicolor FISH techniques cannot precisely determine the chromosome regions or breakpoints involved.
Microarray-based comparative genomic hybridization (array CGH) is an efficient and sensitive technique for detecting genome-wide copy number alterations at high resolution [5]. We describe four patients who possess one or more SMCs (a total of eight SMCs in all four patients) that were characterized using a combination of G-banded analysis, FISH, and array CGH. Array CGH not only identified the chromosome of origin of all but two minute SMCs, but it also defined the region(s) and breakpoints of each chromosome involved. In addition, array $\mathrm{CGH}$ revealed unexpected structural SMC complexity that could easily have been missed if FISH and G-banding alone had been used for characterization.

\section{Results (summarized in Table I) \\ Patient I}

This male with wide-spaced nipples, unilateral cryptorchidism, small penis, right clubfoot and left congenital vertical talus had a peripheral blood chromosome analysis performed shortly after birth. Examination of 35 cells demonstrated a normal 46,XY karyotype. He was again evaluated at 14 months of age with findings that also included developmental delay, mild arthrogryposis, skin hyperpigmentation distributed along the lines of Blaschko, a sacral dimple, and an undescended testis on the right. Cranial MRI was normal, but lumbar spine MRI showed cord tethering with hydrosyringomyelia, anterior wedging of the $\mathrm{T} 2$ vertebral body, and incomplete closure of the L5 and S1 posterior vertebral elements. A scrotal skin biopsy taken at the time of orchiopexy was submitted for cytogenetic analysis. Eight of 37 cells were found to contain a large SMC. Array CGH using an expanded coverage microarray (see Methods) detected low-level gain of 100 BAC clones from 3q22.3 through 3qter (Fig. 1A). FISH performed on previously G-banded slides using

Table I: Summary of supernumerary marker chromosomes

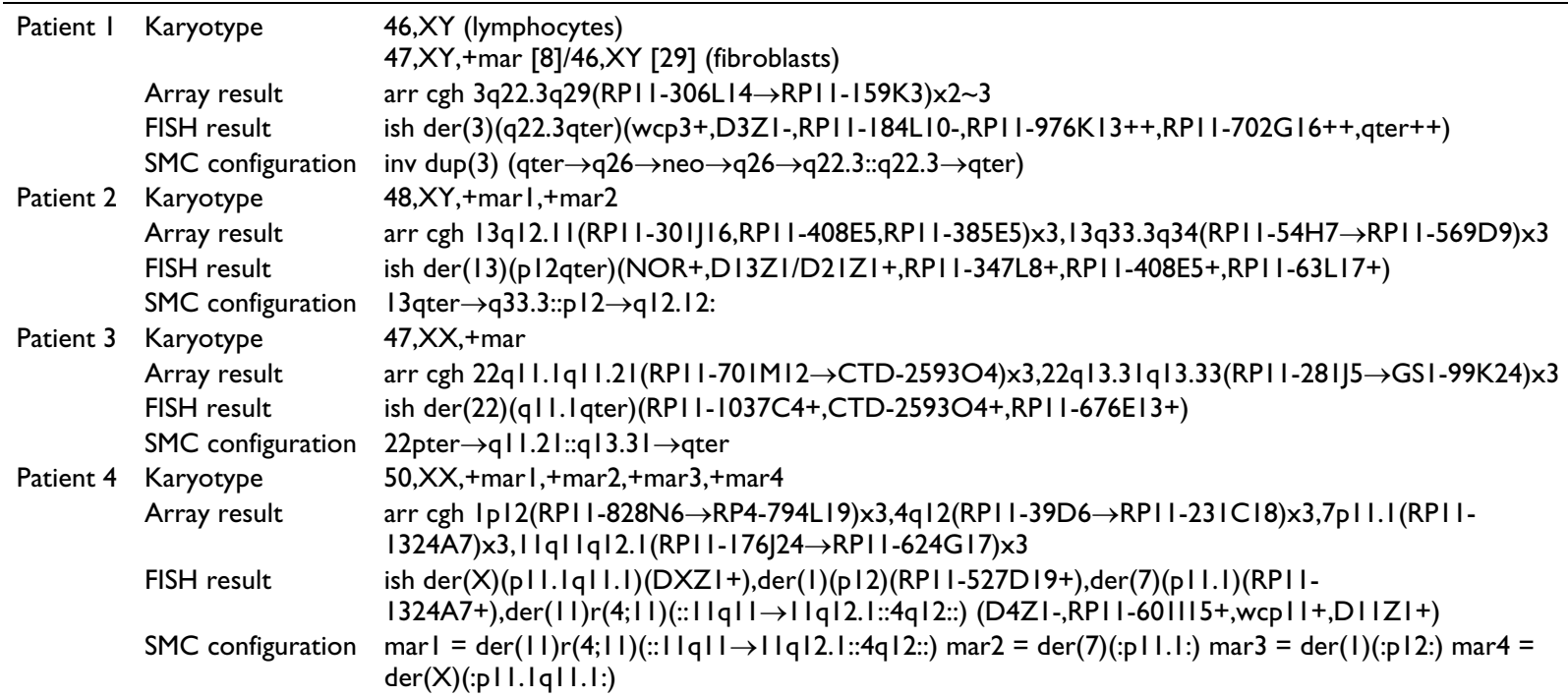



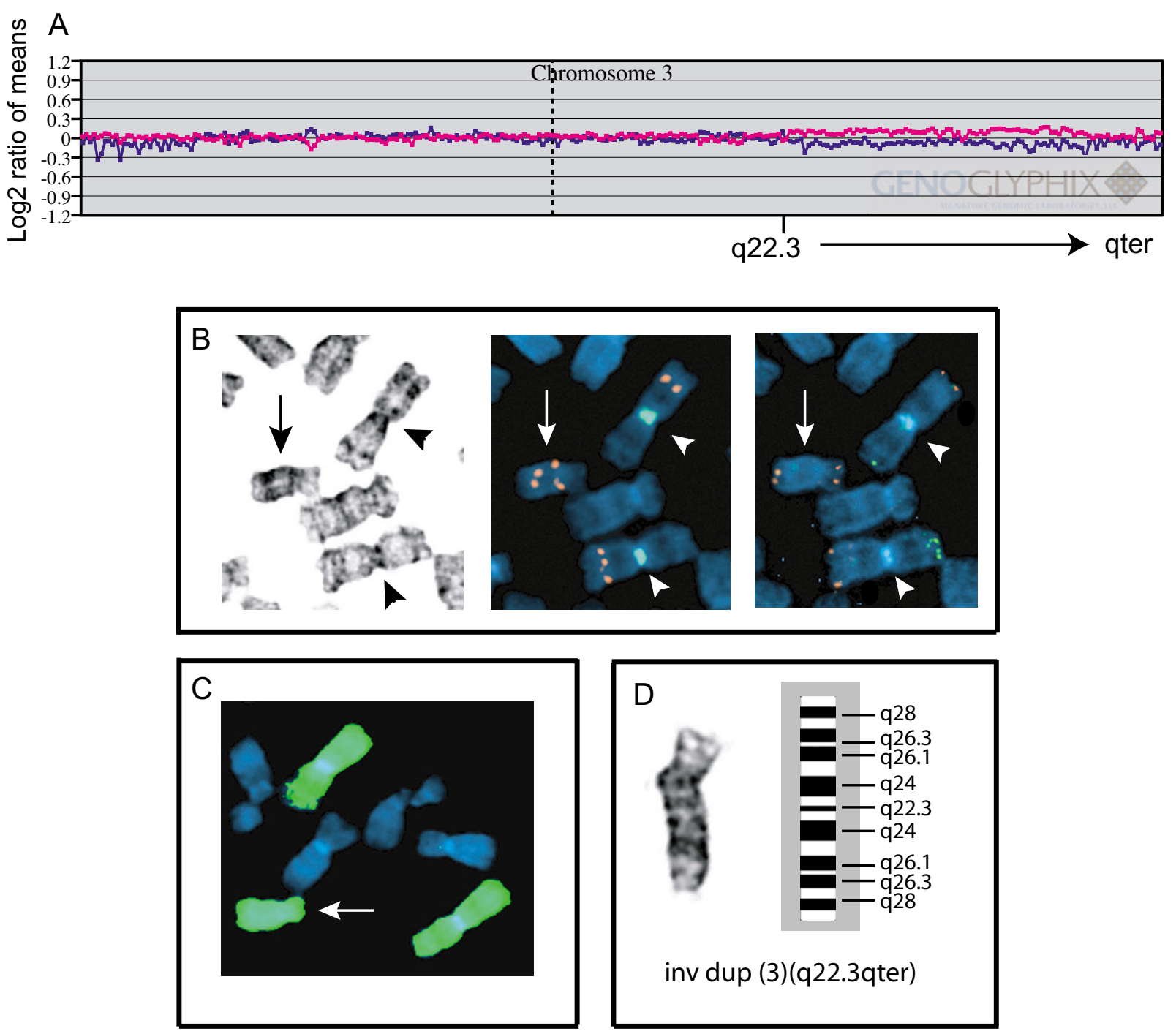

Figure I

Characterization of inv dup(3q) by array CGH and FISH. A. Chromosome 3 array CGH plot. The $X$ axis represents distal $p$ arm to distal $q$ arm (left to right), with the centromere designated by the vertical dotted line. The blue line is a plot of the results from an experiment of Cy5 labeled reference/Cy3 labeled patient, while the pink line is from a dye-reversal experiment (Cy5 patient/Cy3 reference). Slight separation of the plots from q22.3 to qter indicates low-level gain of this region due to marker mosaicism. B. Marker chromosome (arrow) and normal chromosome 3 homologues (arrowheads) from the same metaphase cell that was initially G-banded (left panel), then destained for FISH analyses (middle and right panels). The middle panel shows results of FISH using BAC RPII-976KI3 from 3q25.32 (orange signal) and a chromosome 3 alpha satellite probe (green). Alpha satellite signal is present on the two normal homologues of chromosome 3, but absent from the inv dup(3q). The inv dup $(3 q)$ shows two sets of signals from BAC RPII-976KI3. The right panel shows results of rehybridization using a subtelomeric probe mixture for chromosome 3 (red signal - 3q subtelomeric probe; green signal - 3p subtelomeric probe). Note the $3 q$ subtelomeric signals at both ends of the inv dup $(3 q)$. C. Whole chromosome 3 paint probe, confirming that the marker consists entirely of chromosome 3 material (arrow). D. G-banded image of the inv dup( $3 q$ ), with the corresponding ideogram to the right.

multiple probes from the region of gain confirmed that the marker was derived from the long arm of chromosome 3, and illustrated that the marker had the configura- tion of an inverted, duplicated 3q (Fig. 1B-D). Also consistent with the array CGH results that the gain did not extend more centromeric than $3 q 22.3$, the marker had no 

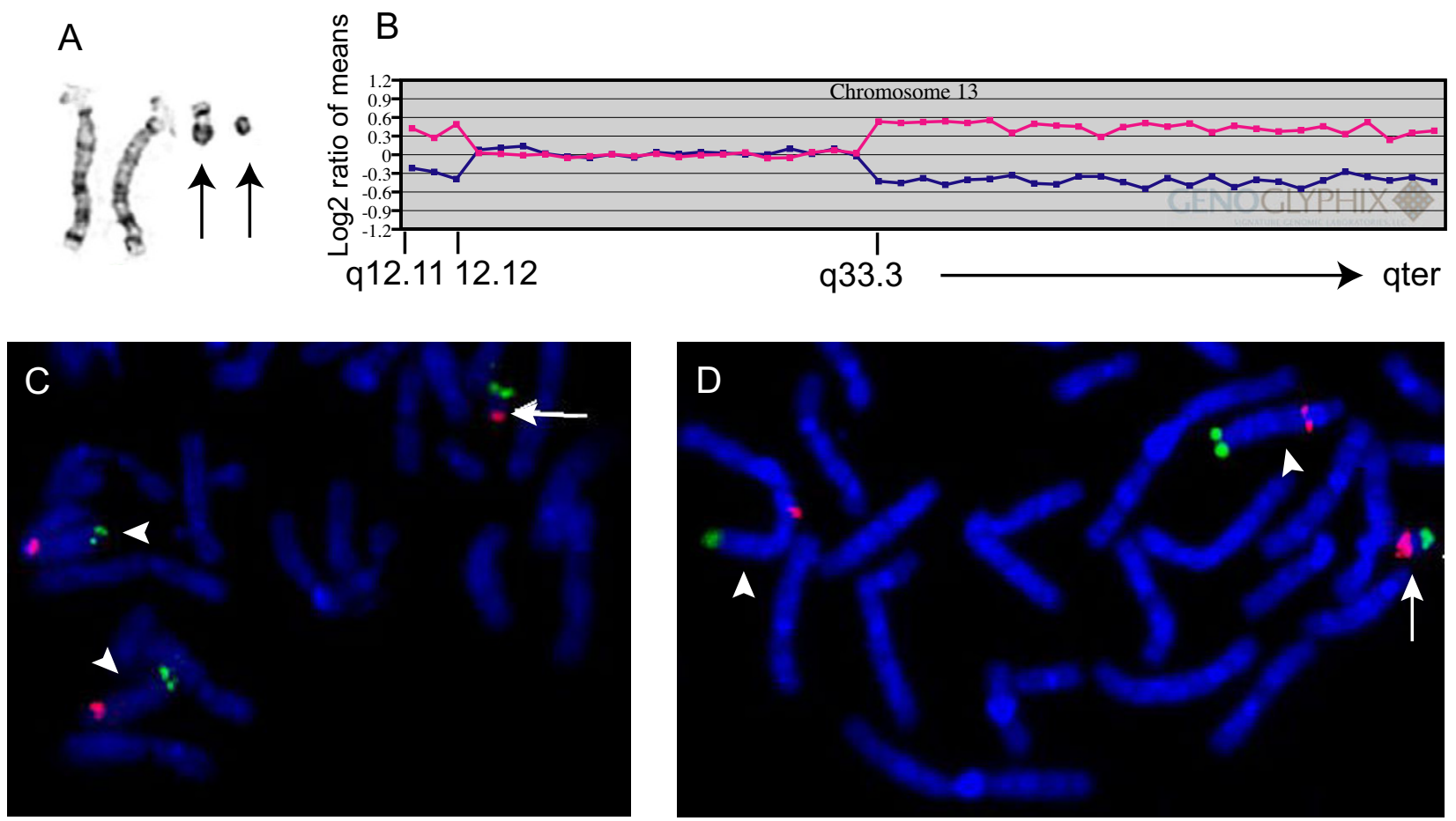

Figure 2

SMCs from patient 2. A. G-banded normal chromosome 13 homologues and SMCs (arrows). B. Array CGH plot showing gains of both proximal and distal I3q, with normal copy number in between. C. FISH using BACs RPII-408E5 from I3qI2.II (red signal) and RPI I-63LI7 from I3q34 (green signal) shows signal from both BACs on the large SMC (arrow), as well as both normal homologues of chromosome I 3 (arrowheads). D. FISH using BACs RPII-347L8 from I3q I2.I3 (red signal) and RPII$63 \mathrm{LI} 7$ (green) again confirms the presence of both proximal and distal I3q in the large SMC (arrow).

detectable chromosome 3 alpha satellite DNA by FISH (Fig. 1B). Although we cannot absolutely exclude the possibility that the marker contains centromeric material from another chromosome, no other gains were detected by array CGH, and G-banded analysis showed a prominent constriction at one end of the marker at band q26, indicating the likely presence of a neocentromere in that location. The combined results of G-banded analysis, array CGH, and FISH were most consistent with the following configuration of the marker: inv $\operatorname{dup}(3)$ (qter $\rightarrow$ q26 $\rightarrow$ neo $\rightarrow$ q26 $\rightarrow$ q22.3::q22.3 $\rightarrow$ qter).

Parental chromosome analyses were not performed.

\section{Patient 2}

A peripheral blood karyotype was performed on a 2 yearold male with moderate global developmental delay and bilateral anterior segment dysgenesis of the eye in the form of the Axenfeld-Rieger anomaly. In addition, he had macrocephaly, a past history of bilateral inguinal hernias, and several depigmented macules. An MRI was significant for a short, thick corpus callosum, prominent perivascular spaces with thinning of the gray matter, and an enlarged posterior fossa. All 20 cells examined from peripheral blood demonstrated a 48,XY,+mar1,+mar2 karyotype (Fig 2A). The larger marker was approximately one-half the size of a G-group chromosome, and G-banded analysis suggested the presence of satellites. The second marker consisted of a minute fragment. Array CGH using a pericentromeric microarray (see Methods) detected a singlecopy gain of 20 BAC clones (approximately $5.3 \mathrm{Mb}$ ) from the pericentromeric region of the long arm of chromosome 13 (data not shown). Additional analysis using a targeted microarray (see Methods) revealed not only a gain of the pericentromeric region of chromosome 13, but also single copy gain of approximately $5.5 \mathrm{Mb}$ from the subtelomeric region of chromosome 13 (13q33.3 to q34) (Fig. 2B). The intervening region of chromosome 13 covered by this array (13q14.2 to 13q33.1) did not show copy number alterations (Fig. 2B). FISH using probes from both the proximal (RP11-408E5, 13q12.11 and RP11-347L8, 13q12.13) and distal (RP11-63L17, 13q34) regions of $13 q$ gain confirmed the origin of the larger SMC (Fig. 2C and 2D). Both BACs from proximal 13q hybridized to one arm of the larger SMC, whereas the 13q34 sub- 
telomeric BAC probe hybridized to the opposite arm of the larger SMC. FISH using a probe from the nucleolar organizing region (NOR) hybridized within the middle of the larger SMC, apparently flanked by the $13 \mathrm{q}$ proximal long arm segment on one side and by the $13 \mathrm{q}$ telomeric segment on the other side (data not shown). Additional FISH using a centromere probe for chromosomes 13 and 21 (D13Z1/D21Z1) showed hybridization only to the larger SMC (data not shown). Thus, none of the probes showed hybridization to the minute SMC, and its origin remains unknown. Based on the combined results of array CGH and FISH, the larger SMC appears to have the following configuration: $13 \mathrm{qter} \rightarrow \mathrm{q} 33.3:: \mathrm{p} 12 \rightarrow \mathrm{q} 12.12:$.

Analysis of 60 peripheral blood metaphase cells from both parents did not show either of the SMCs.

\section{Patient 3}

A peripheral blood karyotype from this term newborn female with low birthweight, hydrocephalus, possible partial agenesis of the corpus callosum, preauricular pits, and total anomalous pulmonary venous return showed a small mono-satellited SMC in all 20 metaphase cells examined (Fig. 3A). Array CGH using the pericentromeric microarray detected a single-copy gain of approximately $3.8 \mathrm{Mb}$ of the proximal long arm of chromosome 22 from q11.1 to q11.21 (data not shown), including the VCFS/ DiGeorge syndrome critical region (DGS1). Additional analysis using the expanded coverage microarray revealed not only the gain of proximal 22q, but also single-copy gain of approximately $5.2 \mathrm{Mb}$ from $22 \mathrm{q} 13.31$ to $22 \mathrm{q} 13.33$ (Fig. 3B). The intervening region of chromosome 22, from q11.21 to q13.31, showed no copy number alterations. FISH using BAC clones from both the proximal (RP111037C4, 22q11.1 and CTD-2593O4, 22q11.21) and distal (RP11-676E13, 22q13.33) regions of 22q gain confirmed the array findings (Fig. 3C and 3D). Both probes hybridized to the marker in all 60 cells examined. Thus, the most likely configuration of this SMC is:

A
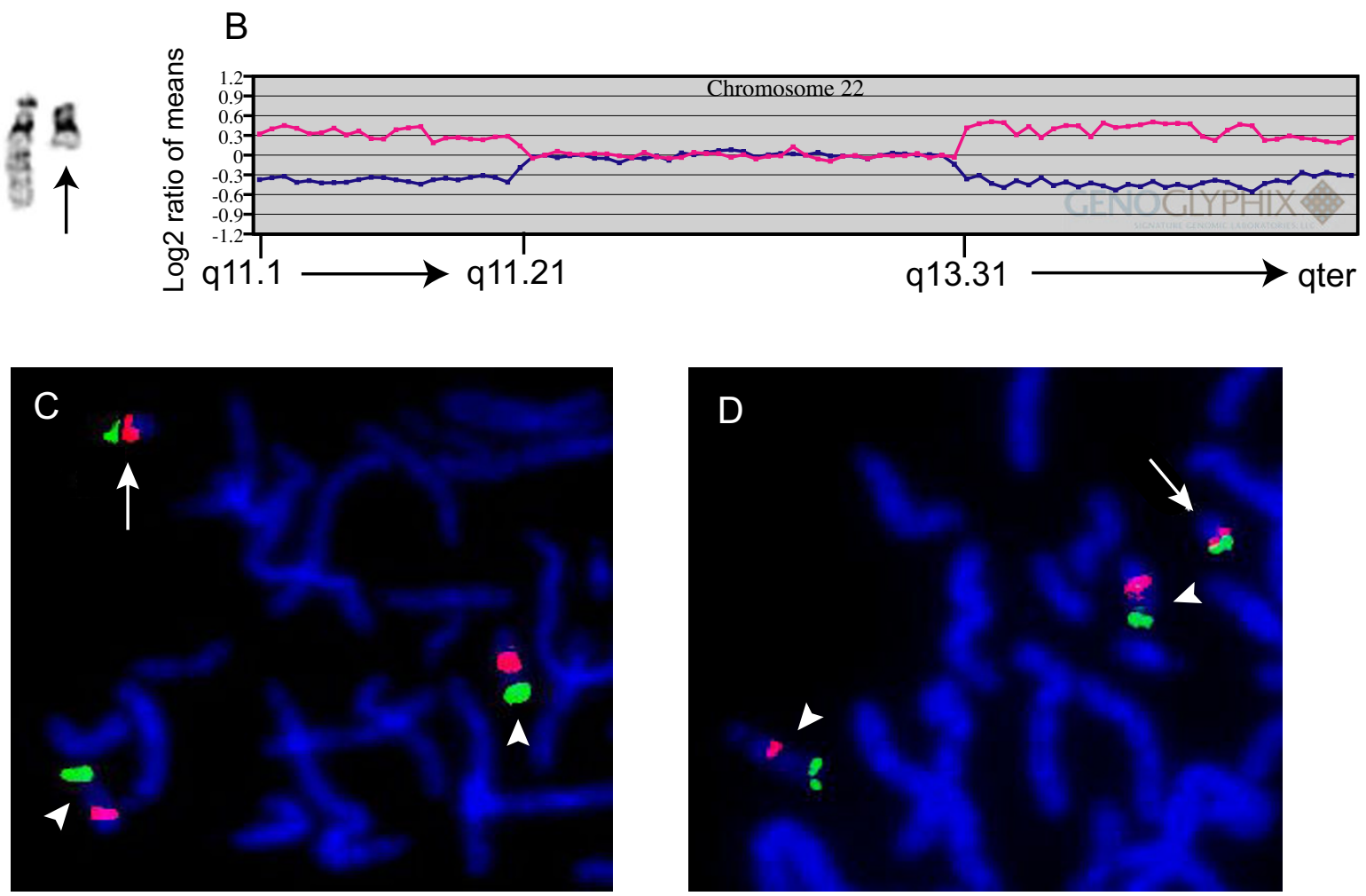

Figure 3

Chromosome 22 SMC from patient 3. A. G-banded normal chromosome 22 homologues and SMC (arrow). B. Array $\mathrm{CGH}$ plot showing gains of both proximal and distal 22q, but not the intervening region between $22 \mathrm{qI}$ I.2I and qI3.3I. C. FISH using BACs RPII-I037C4 from 22q I I.I (red signal) and RPI I-676EI3 from 22qI3.33 (green signal) shows signal from both BACs on the SMC (arrow), as well as both normal homologues on chromosome 22 (arrowheads). D. FISH using BACs CTD259304 from 22qI I.2I (red) and RPI I-676EI3 (green) again confirms the presence of both proximal and distal 22q in the SMC (arrow). 
22pter $\rightarrow \mathrm{q} 11.21:: \mathrm{q} 13.31 \rightarrow \mathrm{qter}$. Parental chromosome analyses were not performed.

\section{Patient 4}

A prenatal ultrasound performed on this female fetus revealed bilateral cleft lip anomaly, ventriculomegaly, and possible agenesis of the corpus callosum. A 48,XX,+2mar/ $49, \mathrm{XX}+3$ mar karyotype was found at amniocentesis performed at another institution. Interphase FISH to screen for aneuploidies of chromosomes 13, 18, 21, X, and Y showed three $\mathrm{X}$ chromosome centromere signals in 40 out of 50 nuclei scored, suggesting that one of the marker chromosomes was derived from the $\mathrm{X}$ chromosome. At birth, bilateral cleft lip anomaly, a flattened nasal profile (nasomaxillary hypoplasia), and upslanting palpebral fissures were noted. MRI of the brain showed fusion of the frontal lobes and thalami, as well as partial agenesis of the corpus callosum, consistent with a semilobar holoprosencephaly. No renal anomalies were detected by ultrasound. An echocardiogram showed normal intracardiac structure with a patent ductus arteriosus. A peripheral blood karyotype confirmed the amniocentesis finding of multiple marker chromosomes, but showed four SMCs in the majority of 20 cells examined. A few cells possibly contained five SMCs, although the minute size of some of the markers made them difficult to distinguish from debris. The SMCs ranged in size from minute to one that was approximately one-third the size of a G-group chromosome, and had the appearance of a ring in some cells. Array CGH using the targeted microarray demonstrated gains of the pericentromeric regions of $1 \mathrm{p}, 4 \mathrm{q}, 7 \mathrm{p}$, and 11q (Fig. 4A). Numbering of the SMCs from 1 to 4 , with SMC 1 representing the largest, and SMC 4 representing the smallest, SMC 1 hybridized with both a chromosome 11 centromere probe (D11Z1) and BAC RP11-601I15 from 4q12 (Fig. 4B), but did not hybridize with a chromosome 4 alpha satellite probe (not shown). SMC 2 hybridized with BAC RP11-1324A7 from 7p11.1 (Fig. 4C), while SMC3 hybridized with BAC RP11-527D19 from $1 \mathrm{p} 12$ (Fig. 4D). SMC 4 hybridized with an X chromosome centromere probe (DXZ1) as expected based on the results from amniocentesis. $\mathrm{X}$ chromosome alpha satellite sequence is not represented on the targeted microarray that was used for array CGH, and the X chromosome did not show any obvious gains, suggesting that this marker may contain only X centromere material, or a very limited amount of euchromatin. Thus, combined array CGH and FISH results revealed the following configurations of the SMCs in this patient:

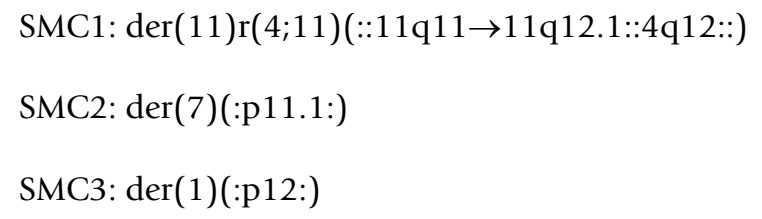

SMC4: $\operatorname{der}(\mathrm{X})(: \mathrm{p} 11.1 \mathrm{q} 11.1:)$

SKY was also performed by an independent laboratory. Results from five cells, each containing two to three SMCs, showed tentative assignments from chromosomes 1, 5, 7, 11 , and 16 (data not shown). FISH did not confirm the presence of chromosome 5 or 16 material in the SMCs. Thus, although SKY classified SMCs derived from chromosomes 1, 7, and 11 material, it did not detect chromosome 4 material in the $\operatorname{der}(11)$ SMC, and SMCs in two cells were incorrectly identified as derived from chromosomes 5 and 16. Parental karyotypes were normal.

\section{Discussion Identification of chromosome of origin of SMCs by array CGH}

Characterization of the SMCs in this study was performed using either a combination of a pericentromeric microarray and a microarray targeted to specific clinically-relevant regions, or a microarray with expanded coverage. The expanded coverage microarray combines all of the coverage of the first two chips, in addition to having expanded clone coverage within and between known microdeleton/ microduplication critical regions. Array CGH was able to identify the chromosome of origin of all but two of the eight SMCs in the four patients who were studied. In one patient (patient 2) who demonstrated two SMCs, array CGH correctly identified the larger of the two markers as a chromosome 13 SMC. FISH using a number of probes from both proximal and distal 13q, including a 13/21 centromere probe, showed hybridization to the larger of the two SMCs only. The second SMC in this patient was minute (see Fig. 2A). In our experience, markers of this size typically fail to show hybridization using 24-color FISH, or yield ambiguous results that are not confirmed with subsequent whole chromosome paints or centromere probes. The X chromosome SMC from patient 4 (see Fig. 4E) that was not identified by array CGH or by SKY was also minute, and may be entirely composed of $\mathrm{X}$ centromere material.

\section{Unexpected structural complexity of SMCs revealed by array CGH}

In addition to correctly classifying the chromosomal origin of all but two minute SMCs, array CGH uncovered complex SMC rearrangements that could have been missed if FISH alone had been used for characterization. The chromosome 13 SMC in patient 2 was shown to contain discontinuous segments of proximal and distal $13 \mathrm{q}$ by array CGH. FISH using a 13/21 centromere probe, although positive in this $\mathrm{SMC}$, would not have distinguished between these two chromosomes, and it would not have given any information with respect to the regions of chromosome 13 contained within the marker. Twentyfour color FISH might have been able to classify the chro- 

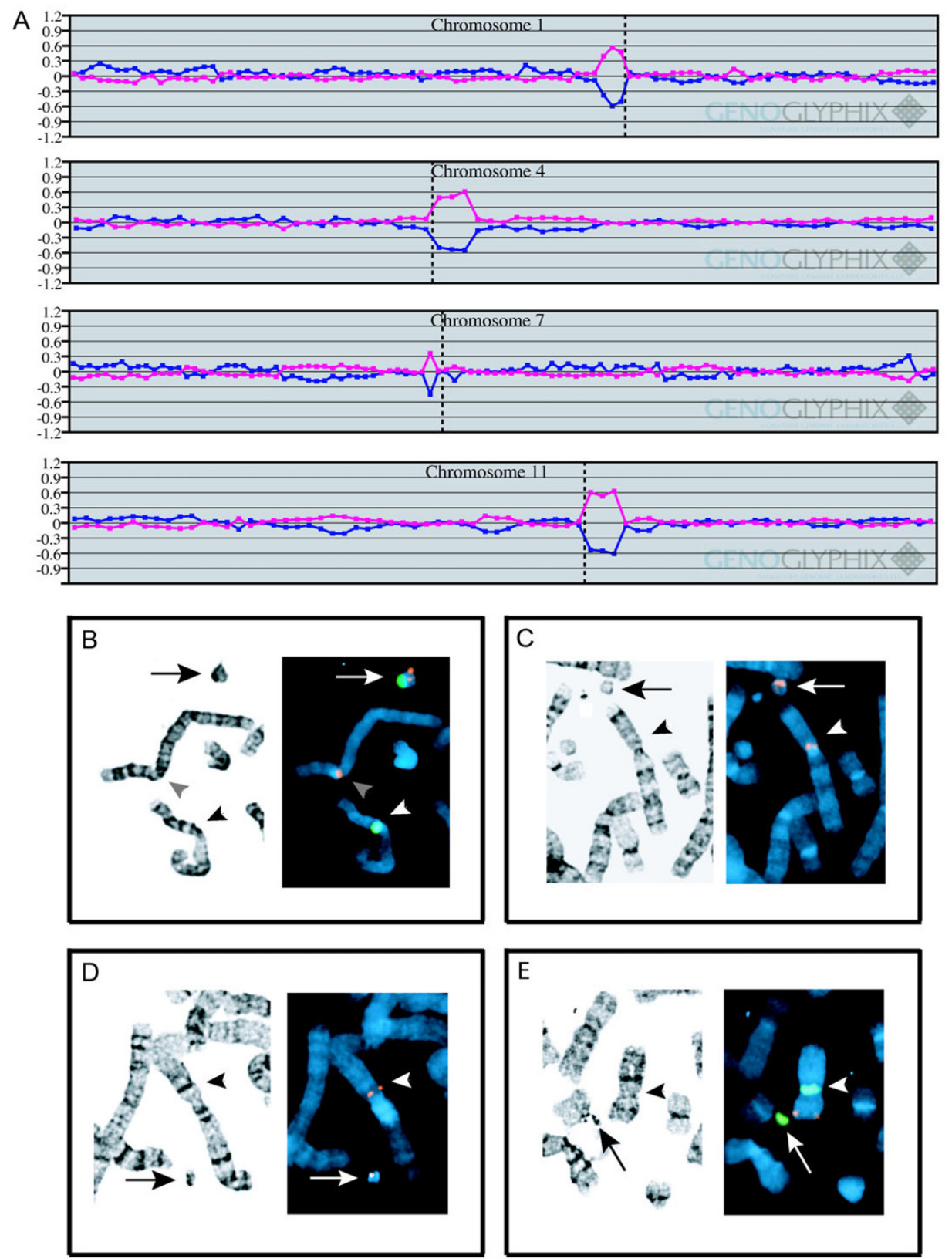

\section{Figure 4}

Characterization of multiple marker chromosomes in patient $\mathbf{4}$ by array $\mathbf{C G H}$ and FISH. A. Chromosome plots showing pericentromeric gains of Ip, 4q, 7p, and I I q detected by array CGH. B. - D. G-banded and corresponding destained FISH images of the marker chromosomes. B. FISH using BAC RPI I-60III 5 from $4 q$ I2 (orange) and a chromosome II alpha satellite probe (green), demonstrating the presence of both chromosome I I centromere and $4 \mathrm{q} / 2$ material in the largest SMC (arrow). One normal homologue of chromosome II (white arrowhead) and one normal homologue of chromosome 4 (gray arrowhead) are also shown. C. FISH using BAC RPI I-I324A7 from 7p I I.I, demonstrating signal on a marker chromosome (arrow) and one of the normal chromosome 7 homologues (arrowhead). D. FISH using BAC RPII-527DI9 from IpI2, demonstrating signal on a marker chromosome (arrow) and one of the normal chromosome I homologues (arrowhead). E. FISH using an $\mathrm{X}$ alpha satellite probe (green) and a probe containing the steroid sulfatase (STS) gene (orange). The smallest marker chromosome contains $X$ centromere material, but not STS (arrow). One normal $X$ chromosome homologue is also shown (arrowhead). 
mosome of origin of this SMC, but it would also not have revealed the discontinuous nature of the chromosome 13 content. An analogous situation was seen with the chromosome 22 SMC (patient 3) that contains discontinuous segments from 22q. Interestingly, in a recent study of twenty-six patients with nonsatellited SMCs characterized by array CGH, only one was found to have this type of SMC complexity [6]. The analphoid SMC derived from 3q could have been classified using 24-color FISH; however, this technique would not have indicated the region of chromosome 3 involved. A multicolor centromere-specific technique would also not have been able to classify this SMC because of the absence of a conventional chromosome 3 centromere. SKY performed on patient 4 , who had multiple SMCs in every cell, resulted in some erroneous chromosome classifications and failed to identify chromosome 4 material in one SMC.

\section{Utility of FISH for complete SMC characterization}

Although array CGH accurately identified the chromosome content of most of the SMCs in the patients presented here, FISH was necessary to determine the structure of the markers. Array CGH correctly defined the segment of $3 \mathrm{q}$ comprising the analphoid SMC in patient 1 , but FISH ultimately characterized the inverted, duplicated configuration of this marker. By array CGH, the SMC in patient 2 was known to contain discontinuous segments of chromosome 13, but the complex structure of the marker, consisting of short arm material flanked on both sides by different segments of long arm material, was only revealed by FISH. Patients 1 and 4 illustrate the utility of performing FISH on previously G-banded slides. Although array CGH correctly detected extra material from both chromosomes 4 and 11 in patient 4 who had multiple SMCs per cell, FISH after G-banding was necessary to demonstrate that the largest SMC was composed of material from both of these chromosomes. FISH of previously G-banded cells also helped characterize the inv $\operatorname{dup}(3 q)$ that was present in only approximately 20 percent of metaphase cells, allowing for targeted analysis of cells known to contain the marker.

\section{SMCs and phenotype}

Although the focus of this study was not to perform an extensive phenotype/SMC correlation, array CGH enabled a more accurate correlation.

\section{Patient I: Neocentric chromosome 3 SMC}

There are at least eight previously reported SMCs that consist of a neocentric inv dup(3q). Seven of these cases had breakpoints that were substantially more distal (q26, q27, or q28) to the q22.3 breakpoint seen in the patient presented here (reviewed in [7]). The inv $\operatorname{dup}(3 \mathrm{q})$ was mosaic in all but one case, and had severe clinical effects in all patients. In addition to these seven patients, there was a recent report of a patient with an analphoid, inv $\operatorname{dup}(3 \mathrm{q})$ and a breakpoint also present in q22.3 [8]. This patient shares some clinical features with the patient presented here and others who have duplications of $3 \mathrm{q}$, including genital abnormalities and various defects in closure of the vertebral column and neural tube. Both patients also exhibited developmental delay and hyperpigmentation along the lines of Blaschko, although the latter finding is not uncommon in patients with chromosomal mosaicism.

\section{Patient 2: SMC derived from chromosome 13}

For many previously reported acrocentric SMCs that were positive by FISH using a D13Z1/D21Z1 probe, the origin of the SMC from chromosome 13 versus chromosome 21 was not determined, confounding phenotypic correlation with these markers. One of the distinctive findings in patient 2 was that of Axenfeld-Rieger anomaly. Mutations in PITX2 (4q25) and FOXC1 (6p25), as well as cytogenetic abnormalities involving these loci, have been found in a wide variety of phenotypes that share features with Axenfeld-Rieger anomaly $[9,10]$. Axenfeld-Rieger anomaly has also been linked to a third locus at 13q14 [9]. This locus may be contained within the SMC found in patient 2 , as there is a gap in clone coverage in this region on the targeted array. It is unclear how an additional copy of this locus would cause the phenotype; however, ocular abnormalities, including anterior chamber anomalies, have been described in patients with trisomy 13 [11].

Patient 3: SMC derived from chromosome 22

A disproportionate number of SMCs are derived from chromosome 22, and these SMCs vary greatly in structure, $22 \mathrm{q}$ content, and phenotypic effect [12]. A subset of chromosome 22 SMCs are associated with cat eye syndrome. These SMCs are bisatellited and contain proximal 22q material, with breakpoints either at the proximal or the distal end of the 22q11 deletion syndrome (DiGeorge/ Velocardiofacial syndrome) critical region [13]. The cat eye syndrome phenotype is highly variable and does not correlate with morphology or size of the bisatellited $22 \mathrm{q}$ SMC. The chromosome 22 SMC reported here in patient 3 was not bisatellited, and contained not only proximal 22q material including the DiGeorge/VCFS critical region, but also distal 22q, from q13.31 to qter. The phenotypic findings in patient 3 have been described in some patients with trisomy $22 /$ mosaic trisomy 22 , although patients with trisomy 22 have multiple additional abnormalities not seen in patient 3 . The findings in patient 3 that have been described in trisomy 22 include hydrocephalus, preauricular pits, and heart defects including anomalous venous return $[14,15]$. Congenital hydrocephalus and hypoplasia of the corpus callosum have also been reported in patients with duplication of 22q13.1 to qter, and 22q13.2 to qter, respectively [16]. 
Patient 4: Multiple SMCs in the same patient

Patient 4 presented with an abnormal phenotype consisting of semilobar holoprosencephaly and bilateral cleft lip, but no other major malformations. This patient was found to have up to four different SMCs in every cell. Whereas a few SMCs have been associated with specific phenotypes, correlation of SMCs with phenotype is problematic due to differences in chromosome of origin, mosaicism, amount of euchromatic material present in the SMC, and the possibility of uniparental disomy of the two normal chromosome homologues. Phenotype/genotype correlations in patients with multiple SMCs may be further complicated by different combinations of SMCs in different cells. Approximately $25-50 \%$ of patients with holoprosencephaly have a numerical or structural chromosome abnormality [17]. Trisomy 13 is a frequent numerical abnormality, and structural abnormalities involving almost every chromosome have been reported in these patients [17]. In one study of holoprosencephaly, all of the cytogenetically abnormal patients had malformations in other organ systems in addition to craniofacial malformations, and two-thirds had malformations in three or more organ systems [18]. The absence of additional malformations in this patient with multiple SMCs suggests that these markers do not contain a significant amount of euchromatin.

\section{Mechanism of formation of SMCs}

Neocentric chromosome 3 SMC

Although neocentromeres derived from almost all human chromosomes have been reported, hotspots of formation seem to exist $[19,20]$. The long arm of chromosome 3 is one region that is disproportionately represented amongst neocentromeres [20]. The most common configuration of neocentric chromosomes, including those involving $3 \mathrm{q}$, is that of a supernumerary inverted duplication of the distal arm of a chromosome $[7,20]$. A frequently proposed mechanism for formation of these markers is that of a Utype exchange between homologous chromosomes during meiosis $[21,20]$; however, DNA polymorphism studies indicate that neocentric SMCs can form either during meiosis or mitosis $[22,23,8]$.

\section{SMCs composed of discontinuous segments of the same} chromosome

Two of the markers described in this study fall into this category. We speculated that the most likely configuration of the SMC 13 was: 13 qter $\rightarrow$ q33.3::p12 $\rightarrow$ q12.12. Alternatively, if the marker had the configuration: $13 \mathrm{q} 33.3 \rightarrow$ qter::p12 $\rightarrow$ q12.12, then this marker may have initially been a ring, and then lost the interstitial segment of $13 q$, between q12 and q33. It is difficult to distinguish between the two configurations, given the very distal breakpoint in $13 q 33$.

\section{Multiple SMCs in the same patient}

There are numerous reports of patients with multiple SMCs, particulary multiple ring chromosomes [24,21,25]. Daniel and Malafiej (2003) hypothesized that these additional markers could arise from a superfluous haploid pronucleus in which there is incomplete digestion of some chromosomes, and transfection of these leftover pieces into the zygote [24]. The high proportion of cases with multiple SMCs that are almost always of different centromeric origin is consistent with this hypothesis.

\section{Conclusion}

Based on the different types of SMCs presented here, array $\mathrm{CGH}$ is the best initial technique for characterization of these abnormal chromosomes, followed by FISH for complete elucidation of marker structure. We and others have found that array CGH using a chip that not only has good pericentromeric coverage, but also adequate overall genome coverage, is necessary for complete SMC characterization $[6,26]$. Improved SMC characterization, facilitated by array CGH, will allow for more accurate SMC/ phenotype correlation in the future. More accurate genotype/phenotype correlation has also been recently reported for ring chromosomes characterized by array CGH in patients who have a 46 chromosome count [27]. Although array CGH using chips that provide comprehensive genome coverage may become the technology of choice for initial characterization of SMCs, G-banded and FISH analyses are still indispensable for determining the structure and level of mosaicism of these chromosomes. G-banded analysis may also be useful for detecting lowlevel mosaic SMCs that could potentially be missed by array CGH.

\section{Methods \\ SMCs}

SMCs were originally identified by conventional cytogenetic analysis performed in the Children's Hospital and Regional Medical Center Cytogenetics Laboratory. Array CGH was subsequently requested by the referring provider to characterize the markers further. Approval for this study was given by the Seattle Children's Hospital Research Institute Institutional Review Board (application \#X-07-047).

\section{Array CGH}

Array CGH on all of the cases was performed using arrays developed and manufactured at Signature Genomic Laboratories, LLC (Spokane, WA). One or more of the following arrays was used in each case: 1) a high-density pericentromeric microarray with coverage of all 43 unique human pericentromeric regions (Signature MarkerChip ${ }^{\mathrm{TM}}$ Version 1.0 [28]); 2) a targeted microarray (SignatureChip ${ }^{\circledast}$ Version $4.0[29,30]$; and 3) an expanded coverage microarray (SignatureChip $\mathrm{WG}^{\mathrm{TM}}$ Version 1.0) [31]. Isola- 
tion and labeling of DNA, microarray hybridization, and microarray analysis were performed as described previously [28].

\section{FISH}

All abnormalities detected by array CGH were confirmed and visualized by metaphase or interphase FISH using one or more BAC clones determined to be abnormal by array CGH [32]. In some cases, FISH using commercially available probes (Abbott Molecular Inc., Des Plaines, IL or Cytocell Technologies, Cambridge, U.K.) was also performed with the ThermoBrite denaturation/hybridization system according to the manufacturer's procedure (Abbott Molecular Inc.). For FISH after G-banding, oil was removed by soaking slides in fresh xylene substitute (Thermo Fisher Scientific, Waltham, MA) for 12 minutes. The slides were then placed in methanol for 12 minutes, air-dried, rehydrated in an ethanol series, fixed in $1 \%$ formaldehyde/1 $\times$ PBS/50 mM MgCl 2 for 7 minutes, washed in $1 \times$ PBS for 5 minutes, dehydrated in an ethanol series, and air-dried before hybridization using the ThermoBrite system.

\section{Spectral Karyotyping (SKY)}

SKY was performed using Applied Spectral Imaging, Inc. (Vista, CA) SkyPaint ${ }^{\circledR}$ probes according to the manufacturer's protocol. Image acquisition was accomplished using the SpectraCube ${ }^{\circledast}$ spectral imaging system (Applied Spectral Imaging, Inc., Vista, CA) according to the manufacturers' instructions.

\section{List of abbreviations}

Array CGH: microarray comparative genomic hybridization; FISH: fluorescence in situ hybridization; SKY: spectral karyotyping; SMC: supernumerary marker chromosome.

\section{Competing interests}

Beth Torchia is a salaried employee of Signature Genomic Laboratories.

\section{Authors' contributions}

$\mathrm{KT}, \mathrm{KO}$, and BT directed the cytogenetic studies, interpreted the results, and drafted the manuscript. $\mathrm{MH}, \mathrm{AH}$, IG, and MR contributed to the phenotype/genotype correlations and helped revise the manuscript. TN interpreted the SKY results and helped revise the manuscript. All authors read and approved the final manuscript.

\section{Acknowledgements}

We thank Louisa Emery-Chen and Christine Clarke for excellent technical support. Catie Beattie and Stephanie Wallace contributed to the clinical care of some of these patients as well.

\section{References}

I. Douet-Guilbert N, Marical H, Pinson L, Herry A, Le Bris MJ, Morel F, De Braekeleer M: Characterisation of supernumerary chromosomal markers: a study of I 3 cases. Cytogenet Genome Res 2007/ 02/03 edition. 2007, I | 6( I-2): |8-23.

2. Brecevic L, Michel S, Starke H, Muller K, Kosyakova N, Mrasek K, Weise A, Liehr T: Multicolor FISH used for the characterization of small supernumerary marker chromosomes (sSMC) in commercially available immortalized cell lines. Cytogenet Genome Res 2006/09/07 edition. 2006, I | 4(3-4):3 I 9-324.

3. Nietzel A, Rocchi M, Starke H, Heller A, Fiedler W, Wlodarska I, Loncarevic IF, Beensen V, Claussen U, Liehr T: A new multicolorFISH approach for the characterization of marker chromosomes: centromere-specific multicolor-FISH (cenM-FISH). Hum Genet 2001/05/17 edition. 200I, I 08(3): I99-204.

4. Pietrzak J, Mrasek K, Obersztyn E, Stankiewicz P, Kosyakova N, Weise A, Cheung SW, Cai WW, von Eggeling F, Mazurczak T, Bocian $\mathrm{E}$, Liehr T: Molecular cytogenetic characterization of eight small supernumerary marker chromosomes originating from chromosomes $2,4,8,18$, and 21 in three patients. J Appl Genet 2007/05/15 edition. 2007, 48(2): 167-175.

5. Shaffer LG, Bejjani BA, Torchia B, Kirkpatrick S, Coppinger J, Ballif BC: The identification of microdeletion syndromes and other chromosome abnormalities: cytogenetic methods of the past, new technologies for the future. Am J Med Genet C Semin Med Genet 2007/I0/03 edition. 2007, I 45(4):335-345.

6. Baldwin EL, May LF, Justice AN, Martin CL, Ledbetter DH: Mechanisms and consequences of small supernumerary marker chromosomes: from Barbara McClintock to modern genetic-counseling issues. Am J Hum Genet 2008/02/07 edition. 2008, 82(2):398-410.

7. Liehr T, Utine GE, Trautmann U, Rauch A, Kuechler A, Pietrzak J, Bocian E, Kosyakova N, Mrasek K, Boduroglu K, Weise A, Aktas D: Neocentric small supernumerary marker chromosomes (sSMC)--three more cases and review of the literature. Cytogenet Genome Res 2007/09/29 edition. 2007, I I 8( I):3 I-37.

8. Gimelli G, Giorda R, Beri S, Gimelli S, Zuffardi O: A large analphoid invdup(3)(q22.3qter) marker chromosome characterized by array-CGH in a child with malformations, mental retardation, ambiguous genitalia and Blaschko's lines. Eur J Med Genet 2007/06/I5 edition. 2007, 50(4):264-273.

9. Alward WL: Axenfeld-Rieger syndrome in the age of molecular genetics. Am J Ophthalmol 2000/09/27 edition. 2000, I30(I): 107-II5.

10. Martinez-Glez V, Lorda-Sanchez I, Ramirez JM, Ruiz-Barnes P, Rodriguez de Alba M, Diego-Alvarez D, Ramos C, Searby CC, Nishimura DY, Ayuso C: Clinical presentation of a variant of AxenfeldRieger syndrome associated with subtelomeric 6p deletion. Eur J Med Genet 2006/12/13 edition. 2007, 50(2): I20-127.

II. Schinzel A: Chromosome 13. In Catalogue of Unbalanced Chromosome Aberrations in Man 2nd edition. New York, Walter de Gruyter GmbH \& Co.; 2001:590.

12. Bartsch O, Rasi S, Hoffmann K, Blin N: FISH of supernumerary marker chromosomes (SMCs) identifies six diagnostically relevant intervals on chromosome $22 \mathrm{q}$ and a novel type of bisatellited SMC(22). Eur J Hum Genet 2005/03/10 edition. 2005, I 3(5):592-598.

13. McTaggart KE, Budarf ML, Driscoll DA, Emanuel BS, Ferreira P, McDermid HE: Cat eye syndrome chromosome breakpoint clustering: identification of two intervals also associated with 22q I I deletion syndrome breakpoints. Cytogenet Cell Genet 1998/09/08 edition. 1998, 8 I (3-4):222-228.

14. Crowe CA, Schwartz S, Black CJ, Jaswaney V: Mosaic trisomy 22: a case presentation and literature review of trisomy 22 phenotypes. Am J Med Genet 1997/09/05 edition. 1997, 7 I(4):406-4I3.

15. Bacino CA, Schreck R, Fischel-Ghodsian N, Pepkowitz S, Prezant TR, Graham JMJr.: Clinical and molecular studies in full trisomy 22: further delineation of the phenotype and review of the literature. Am J Med Genet 1995/05/08 edition. 1995, 56(4):359-365.

16. Schinzel A: Chromosome 22. In Catalogue of Unbalanced Chromosome Aberrations in Man New York, Walter de Gruyter GmbH \& Co.; 2001:880-883.

17. Muenke M, Beachy PA: Holoprosencephaly. In The Metabolic and Molecular Bases of Inherited Disease Volume IV. 8th edition. Edited by: Scriver CR, Beaudet AL, Sly WS, Valle D. New York, McGraw-Hill; 2001:6203-6230. 
18. Olsen CL, Hughes JP, Youngblood LG, Sharpe-Stimac M: Epidemiology of holoprosencephaly and phenotypic characteristics of affected children: New York State, 1984-1989. Am J Med Genet 1997/I2/3| 23:48 edition. 1997, 73(2):217-226.

19. Marshall OJ, Chueh AC, Wong LH, Choo KH: Neocentromeres: new insights into centromere structure, disease development, and karyotype evolution. Am J Hum Genet 2008/02/07 edition. 2008, 82(2):261-282.

20. Warburton PE: Chromosomal dynamics of human neocentromere formation. Chromosome Res 2004/08/04 edition. 2004, 12(6):617-626.

21. Liehr T, Claussen U, Starke H: Small supernumerary marker chromosomes (sSMC) in humans. Cytogenet Genome Res 2004/ 08/12 edition. 2004, 107(I-2):55-67.

22. Depinet TW, Zackowski JL, Earnshaw WC, Kaffe S, Sekhon GS, Stallard R, Sullivan BA, Vance GH, Van Dyke DL, Willard HF, Zinn AB, Schwartz S: Characterization of neo-centromeres in marker chromosomes lacking detectable alpha-satellite DNA. Hum Mol Genet 1997/08/0 I edition. 1997, 6(8): I I95-1204.

23. Rowe AG, Abrams L, Qu Y, Chen E, Cotter PD: Tetrasomy I5q25->qter: cytogenetic and molecular characterization of an analphoid supernumerary marker chromosome. Am J Med Genet 2000/08/22 edition. 2000, 93(5):393-398.

24. Daniel $A$, Malafiej $P$ : A series of supernumerary small ring marker autosomes identified by FISH with chromosome probe arrays and literature review excluding chromosome 15. Am J Med Genet A 2003/02/25 edition. 2003, I I 7(3):2/2-222.

25. Liehr T, Starke H, Senger G, Melotte C, Weise A, Vermeesch JR: Overrepresentation of small supernumerary marker chromosomes (sSMC) from chromosome 6 origin in cases with multiple sSMC. Am J Med Genet A 2005//2/08 edition. 2006 , I40(I):46-5I.

26. Shaffer LG, Ballif BC, Theisen A, Rorem E, Bejjani BA, Torchia B: In the middle of it all: a centered approach to chromosome analysis. Expert Opin Med Diagn 2008, 2(2):I-8.

27. Rossi E, Riegel M, Messa J, Gimelli S, Maraschio P, Ciccone R, Stroppi M, Riva P, Perrotta CS, Mattina T, Memo L, Baumer A, Kucinskas V, Castellan C, Schinzel A, Zuffardi O: Duplications in addition to terminal deletions are present in a proportion of ring chromosomes: clues to the mechanisms of formation. J Med Genet 2007/II/I7 edition. 2008, 45(3): 147-I54.

28. Ballif BC, Hornor SA, Sulpizio SG, Lloyd RM, Minier SL, Rorem EA, Theisen A, Bejjani BA, Shaffer LG: Development of a high-density pericentromeric region $B A C$ clone set for the detection and characterization of small supernumerary marker chromosomes by array CGH. Genet Med 2007/04/07 edition. 2007, 9(3): $150-162$.

29. Shaffer LG, Kashork CD, Saleki R, Rorem E, Sundin K, Ballif BC, Bejjani BA: Targeted genomic microarray analysis for identification of chromosome abnormalities in 1500 consecutive clinical cases. J Pediatr 2006/07/25 edition. 2006, I49(I):98-102.

30. Signature Genomic Laboratories, LLC [http://signaturegenom ics.com/loci list.html]

31. Signature Genomic Laboratories, LLC. [http://www.signa turegenomics.com/images/pdf/Loci WG.pdf]

32. Bejiani BA, Saleki R, Ballif BC, Rorem EA, Sundin K, Theisen A, Kashork CD, Shaffer LG: Use of targeted array-based CGH for the clinical diagnosis of chromosomal imbalance: is less more? Am J Med Genet A 2005/02/22 edition. 2005, I34(3):259-267.

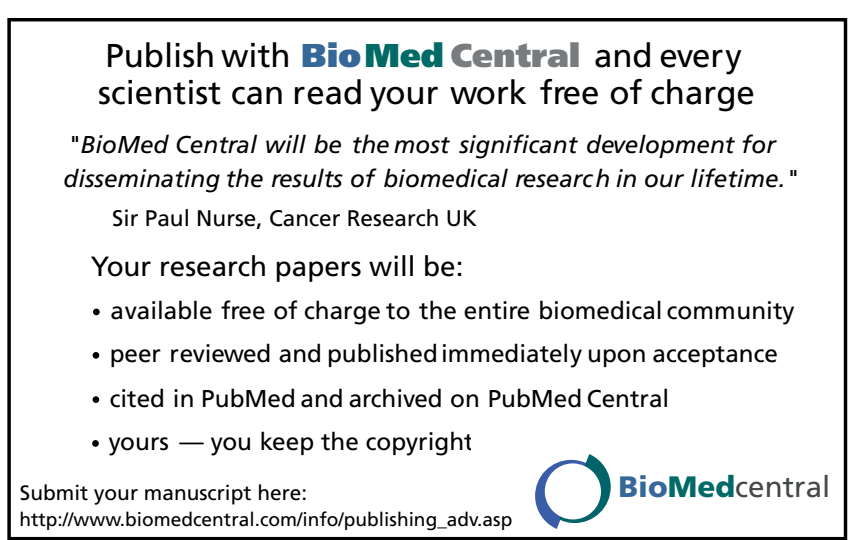

